\title{
Natural products and potent analogs: Capacity to interrupt the Spike-human ACE2 complex, Protease, and RdRp targets of COVID-19 replication via molecular docking and MD Simulations
}

Ritu Mamgain ${ }^{1}$, Garima Mishra ${ }^{1}$, Manisha Kharade ${ }^{2}$ Ninad V. Puranik, and Pratibha

Srivastava ${ }^{1,3^{*}}$

Bioprospecting group

Agharkar Research Institute, Pune, Maharashtra-411004, India

Engineering Unit, Agharkar Research Institute, Pune

${ }^{3}$ Savitribai Phule Pune University, Pune, Maharashtra-411007, India,

Corresponding author email:psrivastava@aripune.org

\begin{abstract}
:
Looking at the severity of SARS-CoV-2 even after the approval of several vaccines like Covishield and Covaxin, there is a concern to find a fruitful remedy for treating infected people in the whole world to stop the spreading of this virus. In this piece of work, we systematically carried out the computational study of potent natural flavonoids Podocarflavone A and Rugosaflavonoid A and their analogs with many targets of COVID-19 such as main Protease (6LU7), S-protein and human ACE2 receptor Complex (6VW1), and RdRp (6M71), which are essential for the survival of nCov-19. MD simulations for 50ns were carried out in TIP3P to check their stability. Thermodynamic stability of the receptor-ligand complexes was evaluated with MMGBSA, and MMPBSA study. The Podocarflavone A and dihydrorugosaflavonoid analogs showed effective binding energy (DS -8.8 to $-8.0 \mathrm{Kcal} / \mathrm{mol}$ ) with S-protein and human ACE2 receptor Complex (6VW1), Protease (6LU7), and RdRp (6M71) of COVID-19. The comparative analysis with several standard antivirals such as remdesivir, oseltamivir, lopinavir, sofosbuvir, tenofovir, galidesivir, and favipiravir displayed that these natural analogs can be better antiviral for the COVID-19. This study demonstrated that halogenated Podocarflavone 2b (MMGBSA -40.93 Kcal/mol, MMPBSA -14.16 Kcal/mol) has comparable results with lopinavir (MMGBSA $-43.15 \mathrm{Kcal} / \mathrm{mol}$, MMPBSA -11.89 $\mathrm{Kcal} / \mathrm{mol}$ ). These compounds could be selected for wet-lab screening to develop as lead molecules in the initial infective stage with spike protein and replicative stage with RdRp of the $\mathrm{n}-\mathrm{Cov}-19$ virus.
\end{abstract}

Significance: These results suggest flavonoids' effectiveness and can be considered for the antiviral screening against COVID-19 to develop them as lead molecules.

\section{Introduction}


The sudden outbreak of novel coronavirus in mid-December 2019 has become a significant health concern worldwide (1). Until April 2021, the World Health Organization (WHO) has reported 1.78 billion infected people worldwide, with the death of 3.97 million people (2). In India, 29.7 million people got infected with nCOV-19, and 3.44 lakh people lost their lives (3). The second wave has shaken the entire India. Many strategies were implemented to control the dissemination of the deadly virus. Among them, social distancing, frequent washing of hands with soap, wearing face masks, several stages of lockdown, isolation of infected people at an early stage, and comprehensive screening of patients traveled to different places were widely executed. Awareness regarding deadly secrets about the virus and accelerated research were considered on the priority list (4). The incubation period of the virus is 1-14 days. The suffered patients are symptomatic (cold, dry cough, breathlessness, and fever) and asymptomatic and behave as carriers for the virus (5). According to the model of respiratory emission, it was found that the virus spread through droplets during sneezing and coughing. It can be as tiny as 1 micron and can travel up to 7-8 meters (6). Later on, it confirmed human-to-human transmission, and the WHO declared this pandemic as an emergency (7). Many variants of SARS-CoV-2 have been generated due to mutation. The virus critically affects the lungs, and in severe cases, it creates blood clots. The delta variant (B.1.167.2) became more lifethreatening, and several people died during the second wave (8).

The highly contagious Novel Coronavirus (n-Cov) is known as Severe Acute Respiratory Syndrome (SARS-CoV-2) and causes influenza-like symptoms. It is a single-stranded RNA (ssRNA) and belongs to the Coronaviridae family. Based on sequence homology, coronavirus shares $79.5 \%$ and $96 \%$ similarity with SARS-CoV and bat coronavirus, respectively (9-11). According to nucleotide sequencing data, SARS-CoV-2 is a member of Betacoronavirus, similar to SARS and Middle East Respiratory Syndrome (MERS) HCoVs. Currently, several specific strains of HCoVs have been noticed, in which 229E and NL63 belong to alphacoronavirus, and OC43, HKU1, SARS, MERS, and SARS-CoV-2 are betacoronavirus (12).

The n-COV has two sets of proteins, structural and non-structural proteins, which play a significant role in the host entry (human), survival, and replication of the virus (Huang et al., 2020). Spike protein (S protein) (Belouzard et al., 2009; Walls et al., 2020), nucleocapsid (N), matrix (M), and envelope (E) are structural proteins. Protease (nsP3 and nsP3) (13) and RNAdependant RNA polymerase (RdRp, nsP12) (Gao et al., 2020) are non-structural proteins. S protein has two subunits S1 and S2. S1 contains the receptor-binding domain, and the S2 unit plays a role in regulating fusion between the virus and host cell membranes. 
S proteins remain at the virus's surface and interact with humans' Angiotensin-converting enzyme 2 (HACE2) present in the pulmonary and parabronchial epithelial cells (14). The binding of human ACE2 with the S-protein of the virus facilitates the virus's entry into the host's circulatory system. Virus ssRNA replicates the virus genomes by taking advantage of the host. When nCoV approaches the ribosome of the epithelial cells in the host, it utilizes the host cells' ribosome to replicate its polyproteins. The second crucial target of $\mathrm{nCoV}$ is the main proteinase (3CLpro) and papain-like Protease, which are thought to be involved in cleaving polyproteins into small products useful for replicating new viruses. For the generation of the daughter RNA genome, the $\mathrm{nCoV}$ expresses RNA-dependent RNA Polymerase (RdRp). It is an important replicase, which catalyzes the complementary RNA strand synthesis using the RNA template. These important proteins, such as $\mathrm{S}$ protein, Protease, and RdRp are crucial targets for therapeutics development.

Understanding the limitation to develop the new effective drug and the emergency period caused by this causative agent $\mathrm{nCoV}$, many drugs are reoriented to treat COVID-19. Recent research documented that hydroxychloroquine and remdesivir potentially curb the replication and infection of SARS-CoV-2 in vitro. Remdesivir's demand has increased several-fold in various countries, including India, during the second wave. Multiple medicines such as ribavirin, lopinavir-ritonavir, and favipiravir are known to treat patients suffering from SARS and MERS. Due to the sequence similarity of n-CoV with SARS-CoV, these drugs are also considered helpful in inhibiting the SARS-CoV-2. Various computational studies were carried out using the library of molecules from different databases to suppress the drastic conditions of disease. Abdo A. Elfiky carried out the molecular docking studies of ribavirin, remdesivir, galidesivir, sofosbuvir, and tenofovir with RdRp (15). Smith and Smith (16) used a supercomputer for docking a library of compounds with viral S protein and with viral S proteinhuman ACE2 interface. Deepak Nair postulated that vitamin B12 binds more efficiently (17). Qamar et al. (18) did the computational studies of Protease with natural products. Wahedi et al. (19) explored the stilbene-based molecules targeting the spike-HACE2 complex. Although vaccines Covishield (AstraZeneca and Oxford) and Covaxin (ICMR and Bharat Biotech) have successfully been implemented in India (20,21) and implemented for immunizing the people to protect them, the treatment of SERS-CoV-2 is still a challenging task.

Crucial role of the S protein-human ACE2 receptor (S-HACE2), Protease, and RdRp in the life-cycle of SARS-CoV-2 virus, prompted us to perform the molecular docking studies of some potent naturally occurring analogs with the S protein-human ACE2 receptor, Protease, and RdRp of the virus using Chimera software. These analogs are prepared in our laboratory 
(Figure 1) and tested against infectious diseases such as Mtb and Chikungunya (22-24). Podocarflavone analogs are also active against Mtb. The results are compared with the various reported antivirals drugs (Figure 2) such as remdesivir (broad-spectrum antiviral), oseltamivir (influenza virus), lopinavir (protease inhibitor), sofosbuvir (antiviral in combination therapy), tenofovir (for HIV), galidesivir (broad-spectrum antiviral), and favipiravir (influenza virus), reported drugs (25-27). For better understanding, Molecular Dynamics (MD) simulations for 50ns and thermodynamic stability by MMGBSA and MMPBSA analysis were performed for known antivirals and natural product analogs selected under this piece of work.

\section{Materials and Methods}

Data and Software

Protein Structure download: 6VW1, 6LU7, 6M71 Source : https://www.rcsb.org/structure

\section{Ligand preparation: Source : Openbabel}

http://www.cheminfo.org/Chemistry/Cheminformatics/FormatConverter/index.html

\section{Molecular Docking:}

Protein preparation: Chimera

a. Licence : UCSF Chimera non-commercial license

b. Source : https://www.cgl.ucsf.edu/chimera/download.html

\section{Simulation and MMPBSA: AMBER 20}

a. Licence:Non-commercial licence

b. Source: https://ambermd.org/GetAmber.php

\section{Computing}

The hardware used is 16 virtual processors on Intel Xeon E5-2620 v3@2.40GHz processor with 32 GB RAM. All softwares are open source and freely available and have been used on Ubuntu operating system.

All input files are given in Supplementary file

\subsection{Protein Selection}

The newly-emerged nCoV-19 proteins are downloaded from the RCSB site https://www.rcsb.org/structure. 6VW1 is the PDB code of S-protein complexed with human ACE2 receptor at $2.68 \AA$ resolution (28). 6LU7 is the PDB code of Protease (Mro) of COVID19 in complex with N3 inhibitor (13). It was a solved structure at $2.16 \AA$ resolution. $6 \mathrm{M} 71$ is the PDB code for RdRp of COVID 19 at $2.9 \AA$ resolution (29). The proteins were prepared for the docking as per the protocol mentioned in the Chimera software tutorial. In short, deleting the nonstandard molecules such as water, the addition of hydrogens and charges, and generating minimized structures using the dock prep module of Chimera 
https://www.cgl.ucsf.edu/chimera/download.html. Molecular mechanics optimize proteins and generate the lowest potential energy and accurate 3D model of the system using the ff14SB force field (29).

\subsection{Ligand Preparation}

The total 15 compounds including seven antivirals and hydroxychloroquine were computationally analyzed against all three therapeutic targets. The structures of small organic molecules were drawn on an open babel site http://www.cheminfo.org/Chemistry/Cheminformatics/FormatConverter/index.html. They were converted into 3D coordinates PDB model of ligands using smile strings, build structure options of Chimera.

\subsection{Molecular Docking}

Chimera software, in association with Autodock Vina http://vina.scripps.edu/download.html, was used for all docking experiments with an optimized model of S-humanACE2 complex (6VW1), M protease (6LU7), and RdRp (6M71) of COVID-19. During the docking, the charged ligand and proteins were used. Grid was generated at ligand-binding pocket based on literature documented.<smiles>COC(=O)c1cc(O)cc2c1C(=O)CC(c1ccc(Cl)cc1)O2</smiles>

$1 a$<smiles>COC(=O)c1cc(O)cc2c1C(=O)CC(c1ccc(Br)cc1)O2</smiles>

$1 b$<smiles>COC(=O)c1cc(O)cc2c1C(=O)CC(c1ccc(OC)cc1)O2</smiles>

1c

Analogs of Dihydrorugosaflavonoids 1a) Chloro-derivative of dihydrorugosaflavonoid; 1b) bromo-derivative of dihydrorugosaflavonoid; 1c) Dihydrorugosaflavonoid<smiles>O=c1cc(-c2ccc(O)cc2)oc2c(-c3ccc(O)cc3)c(O)cc(O)c12</smiles>

$2 a$<smiles>O=c1cc(-c2ccc(O)cc2)oc2c(-c3ccc(Cl)cc3)c(O)cc(O)c12</smiles>

$2 b$<smiles>O=c1cc(-c2ccc(O)cc2)oc2c(-c3ccc(Br)cc3)c(O)cc(O)c12</smiles>

2c<smiles>O=c1cc(-c2ccc(O)cc2)oc2c(-c3ccc(F)cc3)c(O)cc(O)c12</smiles>

2d

Podocarflavone A analogs 2a) Podocarflavone A; 2b) Chloroderivative of Podocarflavone A; 2c) bromo-derivative of Podocarflavone $A ; 2 d$ ) Fluoroderivative of Podocarflavone $A$

Figure 1: Structures of natural flavonoids and their analogs studied for docking studies with COVID-19 therapeutic targets 
<smiles>C=C(C)N[C@H]1CCC(C(=O)OCC)C[C@H]1OC(CC)CC</smiles>

Oseltamivir<smiles>NC(=O)c1cc(F)c[nH]c1=O</smiles>

Favipiravir<smiles>Nc1ncnc2c3c([nH]c12)C1NC(CO)C(O)C3O1</smiles>

Galidesivir<smiles>Cc1cccc(C)c1OCC(=O)NC(Cc1ccccc1)C(O)CC(Cc1ccccc1)NC(=O)C(C(C)C)N1CCCNC1=O</smiles><smiles>CCOC(=O)OCOP(=O)(OCOC(=O)OC(C)C)C(C)OC(C)n1cnc2c(N)ncnc21</smiles><smiles>CC(C)OC(=O)C(C)NP(=O)(OCC1OC(n2ccc(=O)[nH]c2=O)C(C)(F)C1O)Oc1ccccc1</smiles><smiles>CP(=O)(O)Oc1ccccc1</smiles><smiles>C/C=C\N[PH](C)(C)NC(C)C(=O)OCC(CC)CC</smiles>

Figure 2: Structures of antivirals selected for comparative analysis with natural analogs

\subsection{Molecular Dynamics Simulations}

Complex trajectories dynamics in the force field were determined via MD simulations up to 50ns. Complex files (receptors + docked ligands) in the gas phase and solvated phase at $10 \AA$ in TIP3P solvation box were prepared as per Amber version 20 https://ambermd.org/GetAmber.php requirement using PBradii mbondi2, ff14SB, and gaff2 forcefields.

The solvated complex was equilibrated by carrying out a short minimization, 100ps of heating, and 100 ps of density equilibration with weak restraints on the complex followed by 1000ps of constant pressure equilibration at $300 \mathrm{~K}$ through the NVT ensemble incorporating via Langevin dynamics and SHAKE algorithm to limit hydrogen bonds. With a production run via MD 
simulations, trajectories of $50 \mathrm{~ns}$ were constructed. A cutoff threshold distance of $8.0 \AA$ was introduced to separate nonbounded interactions. The stability of the trajectory was analyzed by the analytical computation of structural parameters using the CPPTRAJ module of Amber, and the graph was plotted between RMSD.

\subsection{MMGBSA and MMPBSA Binding Free Energy Estimation}

MMPBSA.py module (30) of AMBER20 was selected to evaluate the solvation free energy and interaction energy for the receptor, ligand, and receptor-ligand complexes. Net binding free energy of the system was calculated as the average of the above-mentioned energies via the MM-PBSA method with its complementary MM-GBSA output of the AMBER to identify the difference between bound and unbound states of solvated conformations of a molecule. Based on the mathematical equation in the literature, equation (1) can be used to calculate the binding free energy.

$\Delta \mathrm{G}^{0}$ bind, solv $=\Delta \mathrm{G}^{0}$ bind, vacuum $+\Delta \mathrm{G}^{0}$ solv, complex $-\left(\Delta \mathrm{G}^{0}\right.$ solv, ligand $+\Delta \mathrm{G}^{0}$ solv, receptor $)$

Poisson Boltzmann (PB) or Generalized Born (GB) equation was used to calculate the solvation energy for all states of the system, which revealed the thermodynamic stability of the complexes.

\section{Results and Discussion}

\subsection{Molecular Docking}

\section{Docking Spike-HACE Receptors}

The S protein interacts with the human ACE2 to initiate viral infection in humans. According to the crystallized structure of S-humanACE2 (6VW1) by Shang et al. (28) the $S_{B}$ domain contains a receptor-binding domain. In the Spike protein, the reported key interacting residues Asn33, His34, Glu37, Asp38, Lys353, Ala387, Gln388, Pro389, Phe390, Arg393, Lys403, Tyr453, Tyr495, Gly496, Phe497, Ser494, and Tyr505 play a critical role in the binding of viral S-protein with its human host ACE2 receptor. The docking scores of the compounds are presented in Table 1. The highest docking score with S-human ACE2 complex protein was obtained by docking of $\mathbf{2} \mathbf{b}(-8.8 \mathrm{Kcal} / \mathrm{mol})$ and $\mathbf{2 a}(-8.6 \mathrm{Kcal} / \mathrm{mol})$, followed by the halogenated dihydrorugosaflavonoid $\mathbf{1 a}(-7.9 \mathrm{Kcal} / \mathrm{mol})$ and $\mathbf{1 b}(-8.1 \mathrm{Kcal} / \mathrm{mol})$. 
Table1: Docking scores of the ligands chosen for the study with S Protein, Protease, and RdRp of COVID-19

\begin{tabular}{|c|c|c|c|}
\hline Compounds & $\begin{array}{l}\text { S-hACE2 (6VW1) } \\
\text { DS Kcal/mol }\end{array}$ & $\begin{array}{l}\text { Protease (6LU7) } \\
\text { DS Kcal/mol-1 }\end{array}$ & $\begin{array}{l}\text { RdRp (6M71) } \\
\text { DS Kcal/mol-1 }\end{array}$ \\
\hline $\mathbf{1 a}$ & -7.9 & -6.7 & -7.3 \\
\hline $\mathbf{1 b}$ & -8.1 & -7.4 & -7.7 \\
\hline $\mathbf{1 c}$ & -7.5 & -7.5 & -7.5 \\
\hline $\mathbf{2 a}$ & -8.3 & -6.4 & -7.9 \\
\hline $\mathbf{2 b}$ & -8.8 & -7.0 & -8.1 \\
\hline $\mathbf{2 c}$ & -8.6 & -7.0 & -8.0 \\
\hline $\mathbf{2 d}$ & -8.3 & -7.1 & -8.1 \\
\hline Favipiravir & -5.2 & -5.6 & -5.4 \\
\hline Galidesivir & -6.7 & -5.7 & -6.3 \\
\hline Lopinavir & -9.2 & -6.0 & -8.0 \\
\hline Oseltamivir & -5.9 & -5.4 & -5.8 \\
\hline Remdesivir & -7.7 & -7.0 & -8.0 \\
\hline Sofosbuvir & -8.7 & -6.8 & -7.1 \\
\hline Tenofovir & -5.8 & -5.6 & -6.3 \\
\hline
\end{tabular}

These podocarflavones $(\mathbf{2 b}, \mathbf{2 c})$ are surrounded with similar residues of the binding pocket and showed interactions with Asp 350 and Arg 393. The interacting residues are presented in Table 2. Spike protein is considered a therapeutic target for both vaccines and drugs. Therefore, it can be mentioned that flavonoids can be considered as inhibitors to the S-protein-human ACE2 complex. They can be useful to inhibit the interaction between S protein and human ACE2 receptors.

\section{Docking with Protease 6LU7}

Dihydrorugosaflavonoid derivatives and podocarflavone have shown docking scores in the range from -7.5 to -6.4 . The rest of the antivirals considered in the study could not display a significant score, except remdesivir showed the binding energy of (-7.0). The interactive residues to protease 6LU7 displayed in the binding pocket are Met 165, Lys 167, Gln 189. All the natural analogs prepared by our group docked nearby and showing interactions. Details of interacting residues are represented in Table 2 . The binding residues nearby glutamine 189 are important, and they form hydrogen bonds with natural analogs of flavonoids. The flavonoids selected for the study are showing positive results and can behave as inhibitors to Protease. 
Table2: Interacting residues of the molecules considered in the study with targets of COVID-19 (S Protein, Protease, and RdRp)

\begin{tabular}{|c|l|l|l|}
\hline Compounds & 6VW1 & 6LU7 & 6M71 \\
\hline $\mathbf{1 a}$ & D350, R393 & $\begin{array}{l}\text { R40, E55, N 180, F } \\
181, \text { R188 }\end{array}$ & K 621, E 811 \\
\hline 1b & D350, R393 & $\begin{array}{l}\text { R40, N 53, F 181, } \\
\text { R188 }\end{array}$ & D 623 \\
\hline 1c & D350, R393 & R40, R188 & K 621, D 623 \\
\hline 2a & D350, R393 & E55, N 84 & E 811 \\
\hline 2b & D350, R393 & E55, Y54 & D 760 \\
\hline 2c & D350, R393 & E55 & K 621 \\
\hline 2d & D350, R393 & P52 & T 556 \\
\hline Favipiravir & N194, Q 101, N103 & N151, D295, T292 & D 761, A762, E811 \\
\hline Galidesivir & E 406 & R 40, R188 & D761, E 811 \\
\hline Lopinavir & Y 385 & R40, R188, & K621 \\
\hline Oseltamivir & D350, D382 & R 40 & K621 \\
\hline Remdesivir & D350 & R 4, K5, D289 & R 556, K621, D760 \\
\hline Sofosbuvir & H 505 & K5, K137, T199 & Y 619 \\
\hline Tenofovir & N33, K 403 & R4, K5 & W617, K621, W800 \\
\hline
\end{tabular}

\section{Docking with RdRp (6M71)}

Most of the compounds reported so far in literature are mostly docked with RdRp. We have selected Chain A for docking (nsP12), as mentioned in the crystal structure by Gao et al. (29). Chain A contains motif A, Motif C, and Motif F (NTP Channel). Motif A contains amino acids starting from Trp 611-Met 626 (TPHLMGWDYPKCDRAM) having the divalent cationbinding residue Asp 618. Motif C contains catalytic residue SDD(Ser759, Asp 760, and Asp 761), which exist between two $\beta$ strands. The NTP channel is having hydrophobic residues (Lys545, Arg 553, and Arg 555). Above mentioned amino acids of 6VW1 are considered for interacting with Remdesivir. Blind docking was performed, and a grid box was created at this site. The standard antivirals remdesivir showed a docking score of -8.1. The rest of the standard antivirals were in the range from -5.2 to -7.1 . The compounds halogenated podocarflavone and natural product podocarflavone A showed the binding energy in the close range of -8.4 to -7.2 (Table 1) and surrounded by these active residues (759-SDD-761, NTP, and D618-D623). The interactive residues are shown in Figure 3. These results indicated that podcarflavone derivatives could be considered as effective antiviral candidates by targeting the RdRp of coronavirus. They may successfully curb the replication of the $\mathrm{n}-\mathrm{CoV}$. 


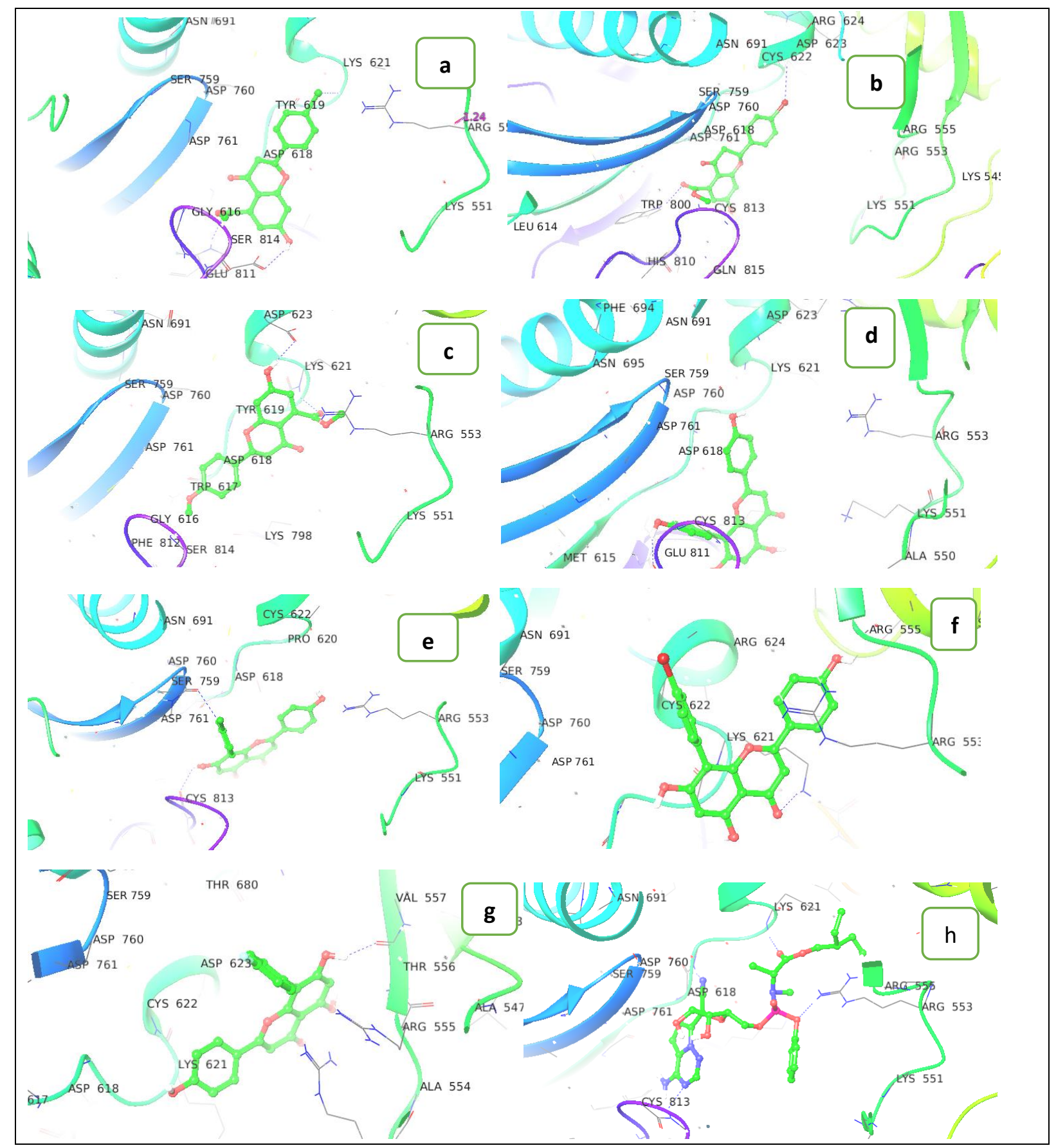

Figure 3: Docking image and Interacting residues of RdRp (6M71) of COVID-19 with Flavonoids a) $1 \mathrm{a} \mathrm{H}$ bond with Glu 811, b) 1 b $\mathrm{H}$ bond with Asp 623, c) 1c $\mathrm{H}$ bond with Lys 621, d) $2 \mathrm{a} \mathrm{H}$ bond with Glu 811, e) $2 \mathrm{~b} \mathrm{H}$ bond with Asp 760, f) $2 \mathrm{c} \mathrm{H}$ bond with Lys 621, g) 2d H bond with Thr 556 h) Remdesivir H bond with Lys 621, Arg 553, Asp 760, Hydrogen bonds have shown in blue dotted line.

The Food and Drug Administration (FDA) approved antivirals selected for the binding with 6VW1, 6LU7, and 6M71 also interacted with these targets, and their images are presented in the supplementary file (Supplementary File 1) 
The supplementary file contains the docking images of compounds with 6VW1 and 6LU7 and docking images of Remdesivir used in the study. It also has an MMPBSA and MMGBSA chart of $\mathbf{2 b}$ with $6 \mathrm{M} 71$.

\subsection{Simulations}

RMSD is a unique parameter to analyze the stability of a protein or protein-drug complex during a time frame. Therefore, stability of flavonoid complex with spike-HACE2, Protease, and RdRp of SARS-CoV-2 was determined by MD simulations. They were compared with trajectories path with standard antivirals such as Flavipiravir, Galidesivir, Lopinavir, Oseltamivir, Remdesivir, Sofosbuvir, and Tefonovir. Trajectories RMSD versus time graph using CPPTRAJ module of Amber 20 were plotted (Daniel et al. 2013) and showed the receptor-ligand complex of all targets spike, Protease, and RdRP (Figure 4). The trajectories for S-HACE2 complex with flavonoids were found to be stable from the beginning except for 2d, as shown in cyan color. They were compared with antivirals Remdesivir and Lopinavir. The trajectories with Protease and RdRp started to stabilize after 5ns and continued in the same state till 50ns with the least fluctuations (Figure 4). These fluctuations may be due to the ligand's adjustment at the active site of the receptors. The results were comparable to standard antivirals. Variations in RMSD values of antivirals were also observed, as in the case of different flavonoids. Dihydrorugosaflavonoid (1c) showed fluctuations with Protease and RdRp. The RMSD value of flavonoids for RdRp came around $1.5 \AA$ except for $\mathbf{2 a}$ and $\mathbf{2 d}$.

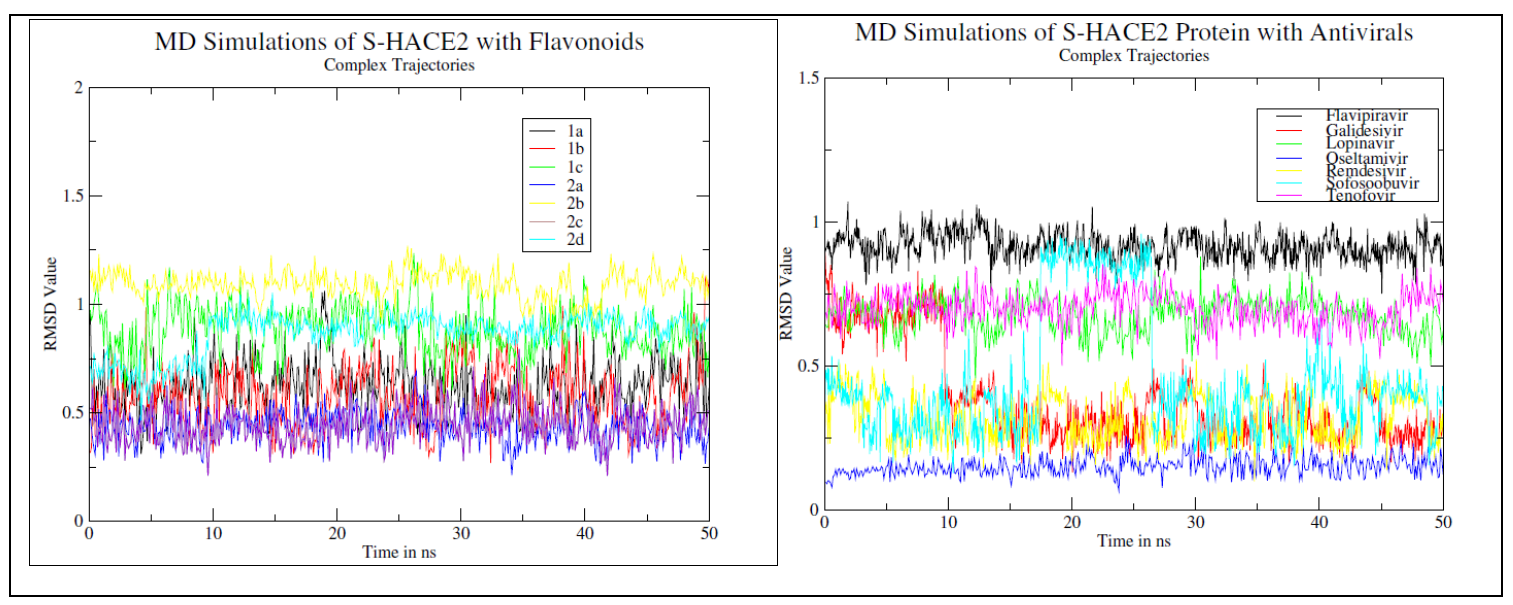




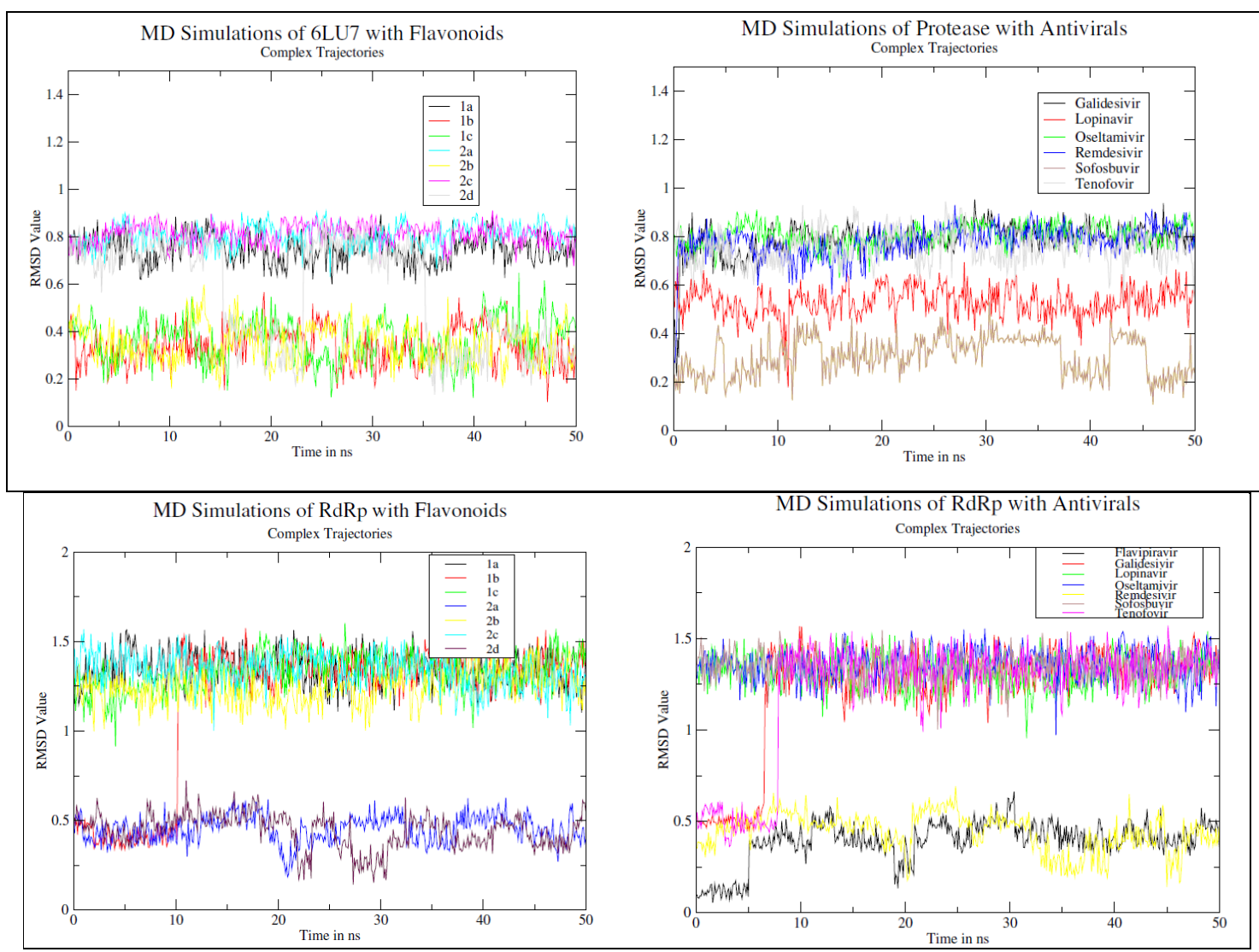

Figure 4: MD simulation graphs of Spike-HACE2, Protease, and RdRp of SARS-CoV-2 with flavonoids (1a-c, 2a-2d) and antivirals.

\subsection{MMPBSA and MMGBSA Binding Free energy estimation}

Determination of intermolecular chemical interactions role in Flavonoids-receptor complex (6VW1, 6LU7, and 6M71) stability, an endpoint MMPBSA/MMGBSA study was performed on the resultant complex trajectories. This was considered not only to support the docking results but also highlight the stability of complex in various parameter conditions such as temperature and pressure. The obtained values of binding free energies in both Poisson Boltzmann (MM-PBSA) and Generalized Born (MMGBSA) are listed in Tables 4, respectively. Both techniques determined very low net binding energies that are in support of the docking results. These low energies are an affirmation of high complex stability. The total binding energy in the case of $\mathbf{2 b}$ with RdRp the MM-GBSA method is lower for the complex i.e., $-40.93 \mathrm{kcal} / \mathrm{mol}$, compared to the MM-PBSA that is $-14.16 \mathrm{kcal} / \mathrm{mol}$ (Table-4). Same compound $\mathbf{2 b}$ displayed the same stability with Spike-HACE2 complex with $-24.98 \mathrm{Kcal} / \mathrm{mole}$ of MMGBSA and -13.78 Kcal/mole of MMPBSA. Favipiravir did not show significant results with protease protein. Among, selected antivirals Lopinavir results are comparable with halogenated Podocarflavone (2b) analogs. These results showed the close contact of receptor 
and ligand and the stability of the trajectories via MD simulations. The results were obtained better than the trajectories of Remdesivir with RdRp and spike proteins.

Table 4: MMPBSA and MMGBSA Calculated Values against S-HACE2, Protease, and RdRp of SARS-CoV-2.

\begin{tabular}{|c|c|c|c|c|c|c|}
\hline Samples & S-HA & CE2 & Pro & ease & $\mathbf{R d}$ & $\mathbf{R p}$ \\
\hline & MMGBSA & MMPBSA & MMGBSA & MMPBSA & MMGBSA & MMPBSA \\
\hline $\mathbf{1 a}$ & $\begin{array}{l}-21.69 \\
(1.32)\end{array}$ & $\begin{array}{l}-9.81 \\
(1.58)\end{array}$ & $\begin{array}{l}-13.25 \\
(1.20)\end{array}$ & $\begin{array}{c}-5.72 \\
(1.74)\end{array}$ & $\begin{array}{l}-23.67 \\
(1.98)\end{array}$ & $\begin{array}{l}-10.78 \\
(2.83)\end{array}$ \\
\hline $1 \mathrm{~b}$ & $\begin{array}{c}-20.78 \\
(0.48)\end{array}$ & $\begin{array}{l}-8.93 \\
(1.62)\end{array}$ & $\begin{array}{l}-15.63 \\
(2.80)\end{array}$ & $\begin{array}{l}-7.85 \\
(1.69)\end{array}$ & $\begin{array}{l}-18.89 \\
(1.54)\end{array}$ & $\begin{array}{c}-8.09 \\
(1.93) \\
\end{array}$ \\
\hline 1c & $\begin{array}{l}-20.81 \\
(1.04)\end{array}$ & $\begin{array}{l}-8.03 \\
(1.77)\end{array}$ & $\begin{array}{l}-10.68 \\
(2.13)\end{array}$ & $\begin{array}{l}-4.61 \\
(2.16)\end{array}$ & $\begin{array}{l}-22.01 \\
(0.58)\end{array}$ & $\begin{array}{l}-9.31 \\
(1.67)\end{array}$ \\
\hline $2 \mathbf{a}(\mathrm{OH})$ & $\begin{array}{l}-21.69 \\
(2.95)\end{array}$ & $\begin{array}{l}-11.23 \\
(1.89)\end{array}$ & $\begin{array}{l}-25.67 \\
(1.12)\end{array}$ & $\begin{array}{l}-10.51 \\
(1.94)\end{array}$ & $\begin{array}{l}-17.21 \\
(1.97)\end{array}$ & $\begin{array}{l}-11.68 \\
(2.81)\end{array}$ \\
\hline $2 \mathrm{~b}(\mathrm{Cl})$ & $\begin{array}{l}-24.98 \\
(2.60)\end{array}$ & $\begin{array}{c}-13.78 \\
(1.43)\end{array}$ & $\begin{array}{l}-20.76 \\
(2.34)\end{array}$ & $\begin{array}{l}-7.23 \\
(3.38)\end{array}$ & $\begin{array}{l}-40.93 \\
(1.21)\end{array}$ & $\begin{array}{c}-14.16 \\
(2.71)\end{array}$ \\
\hline $2 \mathrm{c}(\mathrm{Br})$ & $\begin{array}{c}-24.81 \\
(2.19)\end{array}$ & $\begin{array}{c}-12.93 \\
(2.36)\end{array}$ & $\begin{array}{l}-21.88 \\
(0.89)\end{array}$ & $\begin{array}{l}-10.57 \\
(1.27)\end{array}$ & $\begin{array}{l}-24.34 \\
(1.06)\end{array}$ & $\begin{array}{l}-7.17 \\
(3.08)\end{array}$ \\
\hline $2 d(F)$ & $\begin{array}{l}-24.09 \\
(3.13)\end{array}$ & $\begin{array}{l}-9.87 \\
(4.21)\end{array}$ & $\begin{array}{l}-15.29 \\
(0.84)\end{array}$ & $\begin{array}{l}-4.28 \\
(1.69)\end{array}$ & $\begin{array}{l}-16.82 \\
(1.96)\end{array}$ & $\begin{array}{c}-6.18 \\
(2.97)\end{array}$ \\
\hline Favipiravir & $\begin{array}{r}-16.45 \\
(1.14)\end{array}$ & $\begin{array}{l}-8.91 \\
(3.14)\end{array}$ & NS* & NS* & $\begin{array}{r}-11.36 \\
(3.12)\end{array}$ & $\begin{array}{l}-1.78 \\
(4.54)\end{array}$ \\
\hline Galidesivir & $\begin{array}{l}-14.65 \\
(3.21)\end{array}$ & $\begin{array}{c}-4.78 \\
(1.35)\end{array}$ & $\begin{array}{l}-11.60 \\
(1.68)\end{array}$ & $\begin{array}{l}-2.84 \\
(1.14)\end{array}$ & $\begin{array}{r}-19.12 \\
(2.39)\end{array}$ & $\begin{array}{l}-5.76 \\
(2.44) \\
\end{array}$ \\
\hline Lopinavir & $\begin{array}{l}-29.85 \\
(3.21)\end{array}$ & $\begin{array}{l}-7.24 \\
(3.35)\end{array}$ & $\begin{array}{l}-41.63 \\
(0.92)\end{array}$ & $\begin{array}{l}-14.12 \\
(1.84)\end{array}$ & $\begin{array}{l}-29.85 \\
(1.83)\end{array}$ & $\begin{array}{l}-11.89 \\
(3.36)\end{array}$ \\
\hline Oseltamivir & $\begin{array}{r}-16.37 \\
(2.15)\end{array}$ & $\begin{array}{l}-8.45 \\
(4.96)\end{array}$ & $\begin{array}{l}-9.12 \\
(2.05)\end{array}$ & $\begin{array}{l}-6.49 \\
(2.33)\end{array}$ & $\begin{array}{r}-17.45 \\
(2.12)\end{array}$ & $\begin{array}{l}-4.67 \\
(3.12)\end{array}$ \\
\hline Remdesivir & $\begin{array}{r}-13.84 \\
(3.00)\end{array}$ & $\begin{array}{l}-6.83 \\
(4.73)\end{array}$ & $\begin{array}{c}-14.11 \\
(6.55)\end{array}$ & $\begin{array}{l}-8.98 \\
(7.89)\end{array}$ & $\begin{array}{c}-32.57 \\
(6.55)\end{array}$ & $\begin{array}{l}-9.79 \\
(7.35)\end{array}$ \\
\hline Sofosbuvir & $\begin{array}{r}-42.61 \\
(4.38)\end{array}$ & $\begin{array}{l}-6.89 \\
(6.45)\end{array}$ & NS* & $\mathrm{NS}^{*}$ & $\begin{array}{c}-34.14 \\
(2.48)\end{array}$ & $\begin{array}{l}-6.49 \\
(4.82)\end{array}$ \\
\hline Tenofovir & $\begin{array}{c}-26.02 \\
(2.25)\end{array}$ & $\begin{array}{l}-7.89 \\
(4.81)\end{array}$ & $\begin{array}{c}-16.98 \\
(3.34)\end{array}$ & $\begin{array}{l}-6.51 \\
(3.11)\end{array}$ & $\begin{array}{l}-30.55 \\
(2.07)\end{array}$ & $\begin{array}{l}-7.18 \\
(3.06)\end{array}$ \\
\hline
\end{tabular}

\section{SD in paranthesis NS not significant}

\section{Conclusion}

In the present situation, people are suffering from a deadly pandemic, causing 1.78 billion infected people worldwide, with the death of 3.97million people (2). In India also 29.7M people got infected with nCOV-19, and 3.44 lakh people lost their lives (3). The second wave showed the brutality of virus over people, especially to the young generation. The WHO declared the emergency. During this condition, random trials and repurposing of the FDA approved drugs were considered as the only remedy. The vaccine's arrival was considered life-saving, but the situation was like mayhem in April-May 2021 in India. The patients have to tolerate the side 
effects of the medicine, such as Remdesivir and steroids. The present study of natural product analogs showing an assurance that they can be useful. The flavonoids are already known for their antioxidant potential as well as they are capable of reducing oxidative stress. The compounds selected for the study are already effective against infectious diseases. The docking results are comparable or some way better than known antivirals such as Favipiravir, Lopinavir, Remdesivir, Sofosbuvir, Galidesivir, and Tenofovir. Therefore, their screening against the novel coronavirus will open a new regime of these analogs to be as the lead molecules for COVID-19. The stability of trajectories in MD simulations and lower values of MMPBSA and MMGBSA strongly support the positive outcome of these molecules. Therefore, it can be mentioned that these compounds should be considered for antiviral screening against SARSCoV-2.

Conflict of Interest. The authors have no conflict of interest.

Acknowledgment:

The authors are thankful to the Chimera and Amber software development team for generating user-friendly software. Dr. Ritu Mamgain is grateful to DST-WOSA (WOS-A/CS-107/2018) for financial assistance, and Dr. Garima Mishra is thankful to DST-WOSA (WOS-A/CS$88 / 2019)$

\section{References}

\section{References}

(1) Service. R. F. Coronavirus epidemic snarls science worldwide. Science, 2020, 367, 836-837. doi: 10.1126/science.367.6480.836

(2) WHO. Coronavirus Disease (COVID-19) Pandemic; World Health Organization: Geneva, Switzerland, 2020.

(3) Indian Council of Medical Research Status of COVID-19. 2021

(4) Potdar, V., Cherian, S. S., Deshpande, G. R., Ullas, P.T., Yadav. P.D. et. al. Genomic analysis of SARS-CoV-2 strains among Indians returning from Italy, Iran \& China, \& Italian tourists in India. Indian. J. Med. Res. 2020, 151, 255-60 doi: 10.4103/ijmr.IJMR_1058_20

(5) Park, M., Cook, A., Lim, J. T., Sun, Y., Dickens, B. (2020). A Systematic Review of COVID-19 Epidemiology based on current evidence. J. Clin. Med. 2020, 9 (967). doi: $10.3390 / \mathrm{jcm} 9040967$

(6) Spellberg, B., Haddix, M., Lee, R., Butler-Wu, S., Holtom, P., Yee, H., Gounder, P. Community prevalence of SARS-CoV-2 among patients with Influenza like Illnesses 
presenting to a Los Angeles Medical Center in March 2020. JAMA. 2020, 323 (196667). doi:10.1001/jama.2020.4958

(7) Yang, L. China Confirms Human-to-Human Transmission of Coronavirus, 2020.

(8) Singh, J., Rahman S. A., Ehtesham, N. Z., Hira, S., Hasnain S. E. (2021) SARS-CoV-2 variants of concern are emerging in India. Nature Medicine, 2021 https://doi.org/10.1038/s41591-021-01397-4

(9) Huang, J., Song, W., Huang, H., Sun, Q. (2020). Pharmacological therapeutics targeting RNA-dependent RNA polymerase, proteinase and Spike protein: From Mechanistic studies to clinical trials for COVID-19. J. Clin. Med. 9 (1131). doi:10.3390/jcm9041131

(10) Lu, R., Zhao, X., Li, J., Niu, P., Yang, B., Wu, H., Wang, W., Song, H., Huang, B., Zhu, N. et al. (2020). Genomic characterization and epidemiology of 2019 novel Coronavirus: Implications for virus origins and receptor binding. Lancet, 395 (565574). https://doi.org/10.1016/ S0140-6736(20)30251-8.

(11) Cao, Y. C., Deng, Q. X., Dai, S. X. Remdesivir for severe acute respiratory syndrome coronavirus 2 causing COVID-19: An evaluation of the evidence. Travel Med. Infect. Dis. 2020, 35 (101647). doi: 10.1016/j.tmaid.2020.101647

(12) Zhou, P., Yang, X.-L., Wang, X.-G., Hu, B., Zhang, L., Zhang, W., Si, H.-R., Zhu, Y., Li, B., Huang, C.-L. et al. . A pneumonia outbreak associated with a new coronavirus of probable bat origin. Nature, 2020, 579 270-273,. doi: 10.1038/s41586-020-2012-7.

(13) Jin, Z., Du, X., Xu, Y., Deng, Y. et al. Structure of $M^{\text {Pro }}$ from COVID-19 virus and discovery of its inhibitors. Nature, 2020, 582, 289-293. doi.org/10.1038/s41586-0202223-y.

(14) Walls, A. C., Park, Y.-J., Tortorici, M. A., Wall, A., McGuire, A. T., Veesler, D. Structure, function, and antigenicity of the SARS-COV-2 glycoprotein. Cell, 2020, 180 281-292. doi: 10.1016/j.cell.2020.11.032.

(15) Elfiky, A. A.. Ribavarin, Remedesivir, Sofosbuvir, Galidesivir, and Tenofovir against SARS-CoV-2 RNA-dependent RNA-polymerase (RdRp): A molecular docking study. Life Sciences, 2020, 253 (117592). https://doi.org/10.1016/j.lfs.2020.117592

(16) Smith, M. D., Smith, J. C. (2020). Repurposing therapeutics for COVID-19: Supercomputer-based docking of the SARS-CoV-2 viral spike protein and viral spike protein-human ACE2 interphase. doi.org/10.26434/chemrxiv.11871402.v3 
(17) Narayanan, N., Nair, D. T. Vitamin B12 may inhibit RNA-dependent RNA polymerase activity of nsP12 from COVID-19 virus. IUBMB Life. 2020, 72 (2112-2120) doi:10.20944/preprints202003.0347.v1

(18) Qamar, M. T., Alqahtani, S. M., Alamri, M. A., Chen, L.-L. (2020). Structural basis of SARSCoV-2 3CL pro and anti-COVID-19 drug discovery from medicinal plants. Journal of Pharmaceutical Analysis, 2020, 10 (313-319). doi.org/10.1016/j.jpha.2020.03.009

(19) Wahedi HM, Ahmad S., Abbasi SW., Stillbene based natural compounds as promising drug candidates against Covid-19. J Biomol. Struct. Dyn., 2020, https://doi.org/10.1080/07391102.2020.1762743

(20) Voysey et al., Safety and efficacy of the ChAdOx1 nCoV-19 vaccine (AZD1222) against SARS-CoV-2: an interim analysis of four randomized controlled trials in Brazil, South Africa, and the UK. The Lancet, 2021, 397 (99-111).

(21) Ella R et al., Safety and immunogenicity of an inactivated SARS-CoV-2 vaccine. BBV152: interim results from a double-blind, randomized, multicenter, phase 2 trial, and 3 months follow-up of a double-blind, randomized phase 1 trial. The Lancet, 2021, https://doi.org/10,1016/S1472-3099(21)00070-0

(22) Puranik, N. V., Srivastava, P. First synthesis of rugosaflavonoid and its derivatives and their activity against breast cancer. RSC Advance, 2017, 7 33052-33060. https://doi.org/10.1039/C7RA04971D

(23) Puranik, N. V., Srivastava, P., Swamy, S., Chowdhary, A., Sarkar, D. Molecular modelling studies and in vitro screening of dihydro rugosaflavonoid and its derivatives against Mycobacterium tuberculosis. RSC Advances, 2018, 8, 10634-10643. DOI: $\underline{10.1039 / C 8 R A 00636 A}$

(24) Puranik, N. V., Rani, R., Singh, V. A., Tomar, S., Puntambekar, H. M., Srivastava P. Evaluation of the antiviral potential of halogenated dihydrorugosaflavonoids and molecular modeling with nsP3 protein of Chikungunya virus (CHIKV). ACS Omega, 2019, 4 (20335-20345). https://doi.org/10.1021/acsomega.9b02900

(25) Gautret, P., Lagier, J-C., Parola, P., Hoang, V. T. et al. Hydroxychloroquine and azithromycin as a treatment of COVID-19: results of an open-label non-randomized clinical trial. Int. J. Antimicrob Agents, 2020, 56, 105949 doi.org/10.1016/j.ijantimicag.2020.105949

(26) Sheahan, T. P., Sims, A. C., Zhou, S., Graham. R. L. et al. An orally bioavailable broadspectrum antiviral inhibits SARS-CoV-2 in human airway epithelial cell cultures and 
multiple coronaviruses in mice. Sci. Transl. Med, 2020, doi.org/10.1126/scitranslmed.abb5883.

(27) Wang, M., Cao, R., Zhang, L., Yang, X., Liu, J. et al. Remdesivir and chloroquine effectively inhibit the recently emerged novel coronavirus (2019-nCoV) in vitro. Cell Res. 2020, 30 (269-271). doi: 10.1038/s41422-020-0282-0.

(28) Shang J., Ye G., Shi K., Wan Y., Luo C., Aihara, H, Geng Q., Auerbach A., Li F., Structural basis of receptor recognition by SARS-CoV-2. 2020, Nature, 2020, 581 (221-239).

(29) Gao, Y., Yan, L., Huang, Y., Liu. F. et al. Structure of the RNA-dependent RNA polymerase from COVID-19 virus. Science. 2020 doi.org/10.1126/science.abb7498

(30) Daniel, R. R., Thomas, E. C., III, (2013) PTRAJ and CPPTRAJ: Software for Processing and Analysis of Molecular Dynamics Trajectory Data. J. Chem. Theory Comput., 2013, 9, (3084-3095).

(31) Miller, B. R., III, McGee, T. D., Jr, Swails, J. M., Homeyer, N., Gohlke, H., \& Roitberg, E. A. MMPBSA.py: An efficient program for end-state free energy calculations. Journal of Chemical Theory and Computation, 2012, 8(9), 3314-3321. https://doi.org/10.1021/ct300418h 